\title{
Editorial: Advances in Ungulate Ecology
}

\author{
R. Terry Bowyer ${ }^{* *}$, Vernon C. Bleich ${ }^{2}$, Paul R. Krausman ${ }^{3}$ and Jean-Michel Gaillard ${ }^{4}$ \\ ${ }^{1}$ Institue of Arctic Biology, University of Alaska Fairbanks, Fairbanks, AK, United States, ${ }^{2}$ Department of Natural Resources \\ and Environmental Science, University of Nevada, Reno, NV, United States, ${ }^{3}$ School of Natural Resources and the \\ Environment, University of Arizona, Tucson, AZ, United States, ${ }^{4}$ Laboratoire Biométrie \& Biologie Évolutive, University Claude \\ Bernard - Lyon I, Villeurbanne, France
}

Keywords: population ecology, behavioral ecology, nutritional ecology, conservation, life-histories

\section{Editorial on the Research Topic}

\author{
Advances in Ungulate Ecology
}

\section{INTRODUCTION}

Ungulates possess unique life-histories compared with other mammals, including long lives, large body size, delayed age at first reproduction, iteroparity, small litters with large progeny, high maternal allocation to offspring, and slow-paced life-histories with long generation times (Gaillard et al., 2016). Strong density-dependence, in body growth and recruitment, is typical (Eberhardt, 2002; Bonenfant et al., 2009). Those patterns, and the environments inhabited by ungulates, have been at the forefront of important discoveries in ecology (McCullough, 1979; Bleich et al., 1997), evolution (Boyce, 1988), and conservation (Cain et al., 2008; Krausman and Bleich, 2013). This Research Topic provides an overview and expansion of those advances, especially movement

OPEN ACCESS

Edited and reviewed by: Elise Huchard

UMR5554 Institut des Sciences de

l'Evolution de Montpellier (ISEM), France

*Correspondence: R. Terry Bowyer bowyterr@isu.edu

Specialty section:

This article was submitted to Behavioral and Evolutionary Ecology, a section of the journal

Frontiers in Ecology and Evolution

Received: 02 March 2021

Accepted: 30 March 2021

Published: 27 April 2021

Citation:

Bowyer RT, Bleich VC, Krausman PR and Gaillard J-M (2021) Editorial:

Advances in Ungulate Ecology.

Front. Ecol. Evol. 9:675265.

doi: 10.3389/fevo.2021.675265 ecology (Mysterud et al., 2011), sociality and mating systems (Bowyer et al., 2020), the role of individual heterogeneity in population biology (Plard et al., 2012), responses to predation (Fortin et al., 2009), and evolutionary tradeoffs among biological functions (Gaillard et al., 2000).

Publications are organized into four broad sub-disciplines-Population Ecology, Nutritional Ecology, Behavioral Ecology, and Conservation that integrate them, with some venturing into a more general ecological context such as climate change. These publications offer expansive evolutionary underpinnings that will be of interest to biologists, and provide thought-provoking insights and directions for research.

\section{POPULATION ECOLOGY}

Many studies concentrate on the statistical evaluation of models, which has become a dominant Research Topic. Wisdom et al. provide practical guidelines for research on ungulates, especially those used in population ecology. They state that models should include seven key goals: cooperation between managers and scientists; explicit inference to space with supporting data; use of the appropriate scale for covariates; incorporation of ecologically plausible sets of competing models in development and selection; model evaluation; assessment of relationships with animals and population performance; and reliable interpretations for ecological understanding and use in management.

Many ungulates are partially migratory. Merrill et al. provide a detailed analysis of foraging behavior of migrant and resident North American elk during winter, an ecological context where foraging is constrained by vigilance of elk for gray wolves. They showed that this tradeoff alters foraging benefits between migratory tactics. If changes in winter density differentially influences 
forage-predation tradeoffs of migrant and resident elk, differences in winter foraging, along with grouping patterns, could shape the demographic advantage of a particular migratory tactic.

Gilbert et al. report that summer survival of young Sitka black-tailed deer is primarily determined by black bear predation and is positively influenced by mass at birth and sex. Winter fawn survival is affected by malnutrition in deep-snow winters and is influenced by an interaction between date of birth and snow depth. The prospective demographic analysis shows that adult female survival has the highest potential demographic effect on population growth. Conversely, the retrospective demographic analysis, which accounts for confounding effects of sampling variation, indicates that winter and summer fawn survival are most variable and most influential to variation in population growth.

Although effects of human disturbances on caribou survival are limited to specific regions and areas, Plante et al. detect a negative influence on survival, even at a low level of human development. This research highlights the importance of assessing effects of disturbances at various spatiotemporal scales, and of considering the relative influence of other non-anthropogenic factors to understand dynamics of ungulate populations subjected to a high human disturbance.

Parturition sites and nursery habitat for bighorn sheep constitute important components of habitat use and selection; strong selective pressures affect growth and survival of offspring. Robinson et al. document the birthing habitat for desert and Rocky Mountain bighorn sheep and determine that females raising lambs successfully prefer steep, north facing, rugged terrain in low elevations, and they avoid roads and trails. These results will aid in the management of bighorn sheep populations.

\section{NUTRITIONAL ECOLOGY}

Oates et al. report the importance of nutritional condition of female moose vs. remotely sensed data on vital rates in describing lambda (the finite growth rate). Nutritional condition has the stronger influence on pregnancy rates, parturition success, overwinter survival of adults, and influences survival more so than remotely sensed vital rates. Their work indicates that variation in vital rates and effects of resource limitation in a particular environment may be larger than previously thought.

Barboza et al. tracked body protein use in northern ungulates during late pregnancy when forage is limited and animals are beginning to move to spring and summer ranges to give birth. The capital breeding system of these ungulates relies on routing body proteins to simultaneously sustain maternal function and allocation to reproduction through common metabolic pathways that conserve body mass for survival.

At the population level, mule deer select high forage biomass at the landscape compared with the home-range scale, and during summer rather than spring (Merems et al.). Females that use vegetation with high biomass of preferred forage through spring and summer enter winter in the best condition. Patterns of forage use by ungulates may correlate more strongly with individual fitness than patterns of forage selection.

Pekins calculates the endogenous fat balance of pregnant moose by developing energy-balance equations that account for gestation, winter tick infestation, and lactation under two forage consumption levels. Those variables influence failed calving or calf mortality via a loss of endogenous protein in mid-sized and small cows, but not large ones. This population is confronted with a unique combination of environmental and parasitic conditions associated with a warming climate that affects its survival and reproduction.

Græsli et al. report seasonal differences in body temperature, heart rate, and activity of free-ranging female moose, with lower levels occurring during winter and higher values during summer. Metabolic rates decrease by $60 \%$ from the highest to the lowest point. Hypometabolism during winter is a tactic to reduce energy expenditure during periods with colder climate and limited availability of resources.

\section{BEHAVIORAL ECOLOGY}

Capital and income breeding relates energy used during reproduction to timing of its acquisition, typically focusing on females. Among male ungulates, Apollonio et al. report that capital breeders rely on previously accumulated resources for reproductive allocation. Income breeders use resources acquired primarily during reproductive activities, whereas capital breeders lose mass corresponding to body reserves acquired well before reproductive activities, and allocate a variable amount of energy to deal with different environmental or body conditions. A link exists between capital breeding and degree of polygyny.

Isvaran studies variable mating tactics of the blackbuck, which yielded a novel hypothesis explaining the small size of lek territories. Variation in the size of lek territories can be explained by competition arising from a female bias for mating on central territories. Reduced size of lek territories is likely a consequence of a central mating advantage in large aggregations, and consistent with a reduction in territory size and the evolution of male clustering, which can help explain other mating tactics.

Heffelfinger et al. use machine learning algorithms and resource selection functions to explore tradeoffs associated with reproductive stages in female mule deer. Pre-parturient females, mothers with young at heel, and females having lost their offspring all select areas with greater nutritional resources, that are closer to water, and that present lower predation risk than non-used areas. No tradeoff between safety of offspring and nutrient availability is detected, indicating predation risk and availability of nutritional resources are not mutually exclusive.

Young male white-tailed deer may be more successful when dominant males are absent, but it is uncertain if young males expend effort when those opportunities arise. Monteith et al. identify food intake, hormone levels, body mass, and somatic loss during rut as similar between yearling males that interact with adult males and those that do not. Male deer display 
risk-sensitive reproductive allocation. Reproductive allocation of resources garnered during the prior season are expended to avoid trading off survival for reproduction.

Weckerly reports that size of male-only groups of Roosevelt elk exhibit a positive relationship with male abundance and that the number of males in female groups exhibit an inverse relationship with female abundance. Social factors likely influence sizes of male-only groups and ecological factors probably influence male prevalence in female groups. These outcomes provide additional insights into the evolution of male gregariousness.

Cameron et al. report that calving sites of caribou are characterized by high-quality forage at the time of calving, and by a narrow range of distinct physiographic factors. During spring, pregnant females migrate to areas with high-quality forage, but upon arrival refine selection as a function of environmental stochasticity. Fidelity to calving grounds among caribou is supportive of spatial memory as a navigational mechanism to optimize foraging and energy acquisition.

\section{CONSERVATION}

Creech et al. explore influences of genetic structure, diversity, and isolation and then estimate relative vulnerability to climate change among populations of desert bighorn sheep. Genetic diversity decreases, and differentiation increases with isolation, and these patterns are stronger for native populations than for translocated populations. Native populations occupying intact landscapes are characterized by the lowest vulnerability. Results demonstrate the advantages of using multiple factors to maintain connectivity and potential for adaptation in areas experiencing rapid climate change.

Many ungulate populations exhibit a complex history of isolation and translocation. De Jong et al. report that spatial genetic structure and within-population genetic variation of red deer differ markedly from patterns assumed from present-day abundance and distribution. Those distortions on the genetic landscape can create management dilemmas that cannot be correctly anticipated without baseline genetic monitoring.

Queirós et al. report that non-native or hybrid red deer occur widely among Iberian populations. Mitochondrial introgression occurs across 15 populations, being more frequent in freeranging individuals than in fenced populations but is absent from public-owned populations. Human-mediated translocations of non-native red deer into the Iberian Peninsula highlights the need to implement effective measures to avoid such practices to preserve the endogenous genetic patrimony of Iberian red deer populations.

Opportunities for creating new conservation areas in Africa are restricted by growing human populations and climate change. Whether the current protected-area network captures spatial priorities for conservation of 72 ungulate species is uncertain. Payne and Bro-Jørgensen illustrate how mapping of continent-wide conservation priorities for species can assist land-use planning and guide policies at national levels to enhance conservation.

Patterns of resilience become more difficult to observe as human domination of the Earth destabilizes systems beyond return points. Berger et al. focus on the modalities of ecological disruption that mitigate the changing role of ungulates in landscapes. Much of what was once generally predictable in terms of pattern and process no longer holds. Only messy projections of future community reorganization seem reasonable, whether related to food webs or assembly rules that once governed ungulate communities.

Contributors to this Research Topic provide the groundwork that will lead to important advances in subdivisions of ecology, and further enhance knowledge of these iconic mammals.

\section{AUTHOR CONTRIBUTIONS}

All authors have made substantial contributions to the Editorial and in organizing and editing the Research Topic.

\section{ACKNOWLEDGMENTS}

We thank authors who submitted manuscripts that made the Research Topic on ungulate ecology successful. We are grateful to the referees, acknowledged on the first page of each article, who provided timely and constructive comments on manuscripts. We thank Andrew J. MacIntosh for serving as Editor for a paper when one of the Editors was a co-author.

\section{REFERENCES}

Bleich, V. C., Bowyer, R. T., and Wehausen, J. D. (1997). Sexual segregation in mountain sheep: resources or predation? Wildl. Monogr. 134, 1-50.

Bonenfant, C., Gaillard, J.-M., Coulson, T., Festa-Bianchet, M., Loison, A., Leif, M. G., et al. (2009). Empirical evidence of density-dependence in populations of large herbivores. Adv. Ecol. Res. 41, 313-357. doi: 10.1016/S0065-2504(09)00405-X

Bowyer, R. T., McCullough, D. R., Rachlow, J. L., Ciuti, S., and Whiting, J. C. (2020). Evolution of ungulate mating systems: integrating social and environment factors. Ecol. Evol. 10, 5160-5178. doi: 10.1002/ece3.6246

Boyce, M. S. (1988). Evolution of Life Histories: Theory and Patterns From Mammals, Evolution of Life Histories of Mammals: Theory and Pattern, ed. M. S. Boyce, New Haven, CT: Yale University Press, 3-30.

Cain, J. W. I. I. I., Krausman, P. R., Morgart, J. R., Janse, B. D., and Pepper, M. P. (2008). Responses of desert bighorn sheep to removal of water sources. Wildl. Monogr. 171, 1-32. doi: 10.2193/2007-209

Eberhardt, L. L. (2002). A paradigm for population analysis of long-lived vertebrates. Ecology 83, 2841-2854. doi: 10.1890/0012-9658(2002)083[2841:APFPAO]2.0.CO;2

Fortin, D., Fortin, M. E., Beyer, H. L., Duchesne, T., Courant, S., and Dancose, K. (2009). Group-size-mediated habitat selection and group fusionfission dynamics of bison under predation risk. Ecology 90, 2480-2490. doi: 10.1890/08-0345.1

Gaillard, J.-M., Festa-Bianchet, M., Yoccoz, N. G., Loison, A., and Toigo, C. (2000). Temporal variation in fitness components and population dynamics of large herbivores. Ann. Rev. Ecol. Syst. 31, 367-393. doi: 10.1146/annurev.ecolsys.31.1.367 
Gaillard, J.-M., Lema?tre, J. F., Berger, V., Bonenfant, C., Devillard, S., Douhard, M., et al. (2016). In: Kliman, R. M. (ed.). Encyclopedia of Evolutionary Biology. Oxford: Academic Press, 2, 312-323. doi: 10.1016/B978-0-12-800049-6.00085-8

Krausman, P. R., and Bleich, V. C. (2013). Conservation and management of ungulates in North America. Intern. J. Environ. Stud. 70, 372-382. doi: 10.1080/00207233.2013.804748

McCullough, D. R. (1979). The George Reserve Deer Herd: Population Ecology of a K-selected Species. Ann Arbor, MI: Univ. Michigan Press.

Mysterud, A., Loe, L. E., Zimmermann, B., Bischof, R., Veiberg, V., and Meisingset, E. (2011). Partial migration in expanding red deer populations at northern latitudes $-\mathrm{a}$ role for density dependence? Oikos 120, 1817-1825. doi: 10.1111/j.1600-0706.2011. 19439.x
Plard, F., Bonenfant, C., Delormeb, D., and Gaillard, J.-M. (2012). Modeling reproductive trajectories of roe deer females: fixed or dynamic heterogeneity? Theor. Popul. Biol. 82, 317-328. doi: 10.1016/j.tpb.2012.03.006

Conflict of Interest: The authors declare that the research was conducted in the absence of any commercial or financial relationships that could be construed as a potential conflict of interest.

Copyright (๑) 2021 Bowyer, Bleich, Krausman and Gaillard. This is an open-access article distributed under the terms of the Creative Commons Attribution License (CC $B Y)$. The use, distribution or reproduction in other forums is permitted, provided the original author(s) and the copyright owner(s) are credited and that the original publication in this journal is cited, in accordance with accepted academic practice. No use, distribution or reproduction is permitted which does not comply with these terms. 